\title{
Qualidade química e microbiológica de camarão-rosa comercializado em São Paulo
}

\author{
Andréa Figueiredo Procópio de Moura, Mariana Del Ben Mayer, Marisa Landgraf, \\ Alfredo Tenuta Filho*
}

Departamento de Alimentos e Nutrição Experimental, Faculdade de Ciências Farmacêuticas, Universidade de São Paulo

*Correspondência:

A. Tenuta-Filho

Departamento de Alimentos e

Nutrição Experimental

Faculdade de Ciências Farmacêuticas -

Universidade de São Paulo

Av. Prof. Lineu Prestes, 580, Bloco 14 05508-900, São Paulo, Brasil

E-mail: eetenuta@usp.br
Durante as etapas de captura, manipulação e distribuição, o camarão precisa receber tratamentos adequados visando à manutenção das condições apropriadas de consumo. Com o intuito de avaliar a qualidade de camarão-rosa comercializado no município de São Paulo, amostras do crustáceo foram submetidas a testes de bases voláteis totais (BVT), substâncias reativas ao ácido tiobarbitúrico (TBARs), pH e análises microbiológicas (contagens totais de mesófilos e psicrotróficos). Estas provas, analisadas em conjunto, são consideradas parâmetros adequados no reconhecimento da qualidade do pescado. As amostras analisadas apresentaram valores de $\mathrm{pH}$ de 7,09 a 8,10, BVT entre 27,6 e $73 \mathrm{mgN} /$ $100 \mathrm{~g}$, TBARs de 0,17 a 2,12 mg aldeído malônico/kg, contagem

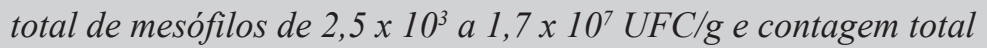
de psicrotróficos variando de $1,1 \times 10^{4}$ a 3,0 $\times 10^{7} \mathrm{UFC} / \mathrm{g}$. Os resultados obtidos sugerem qualidade química insatisfatória para o camarão-rosa analisado, incompativel para um produto considerado comercialmente como fresco.
Unitermos:

- Camarão

- Qualidade

- Microbiologia

- TBARS

- BVT

$\bullet \mathrm{pH}$

\section{INTRODUÇÃO}

Nos últimos 20 anos o consumo per capita de camarão cresceu 66\% nos Estados Unidos, atingindo, em 1996, a marca de 1,13 kg/habitante/ano (National Fisheries Institute, 1998). No Brasil, a pesca extrativa de camarão é maior nas regiões litorâneas, 61 mil toneladas, em 1997 (IBAMA, 2000), e seu consumo chegou a $0,78 \mathrm{~kg} /$ habitante/ano na região metropolitana de Belém - PA, em 1996. Em São Paulo, o consumo per capita de pescado gira em torno de 2,5 kg/habitante/ano (IBGE, 2000).
As operações de bordo na pesca industrial de camarão-rosa envolvem a captura, o manuseio e o armazenamento no barco pesqueiro. As operações realizadas em terra compreendem a descarga, a manipulação e a distribuição para a industrialização ou não, antes de chegar à comercialização do produto.

Durante essas etapas o camarão precisa receber tratamentos adequados visando à manutenção das condições apropriadas de consumo. Bastante críticos são o tempo de duração dessas etapas e a temperatura de manutenção do produto, sendo que a temperatura deve ser sempre conve- 
nientemente tão baixa quanto possível. Os crustáceos, assim como peixes e moluscos, são de reconhecida perecibilidade, podendo representar riscos à saúde do consumidor se não apresentarem a qualidade necessária.

As espécies do gênero Penaeus, conhecidas e indistintamente comercializadas como camarão-rosa $-P$. brasiliensis e P. paulensis - apresentam elevado valor comercial, sendo por isso inacessíveis à maior parte da população. Essa situação, obviamente, gera demanda de consumo menor que a observada em relação a outras espécies de pescado, podendo, portanto, propiciar o uso de práticas comerciais destinadas a estender ao máximo o tempo de vida-útil do camarão-rosa, em detrimento de sua qualidade.

O objetivo do trabalho foi avaliar a qualidade química e microbiológica de camarão-rosa "fresco" comercializado no município de São Paulo.

\section{MATERIAL E MÉTODOS}

\section{Material}

As duas espécies de camarão do gênero Penaeus comercializadas como camarão-rosa - Penaeus brasiliensis e Penaeus paulensis - foram usadas sem distinção, adquiridas em diferentes segmentos do comércio varejista da cidade São Paulo, mercado, supermercado e feira-livre, entre abril e setembro/1999. Foram analisados 10 lotes ( $300 \mathrm{~g}$ cada) com espécimes de tamanho comercial médio (13-15 cm de comprimento; 30-33 g de peso), de várias procedências, sendo 4 lotes oriundos do Estado de Santa Catarina, 5 de São Paulo e 1 do Espírito Santo. As amostras foram transportadas ao laboratório em sacos plásticos envoltos em gelo, em caixa de isopor, sendo analisada a parte comestível.

\section{Métodos}

$\mathrm{O} \mathrm{pH}$ foi eletrometricamente determinado segundo as Normas Analíticas do Instituto Adolfo Lutz (1985) e as bases voláteis totais (BVT), de acordo com o Analytical Methods Committee (1979), sendo expressas em $\mathrm{mgN} / 100 \mathrm{~g}$ amostra. As substâncias reativas ao ácido tiobarbitúrico (TBARS) foram quantificadas como aldeído malônico (mgMA/kg), conforme Vyncke (1970). A contagem total de mesófilos (CTM) e a de psicrotróficos (CTP) foram realizadas segundo Maturin e Puler (1995) e Cousin et al. (1992), respectivamente, com resultados expressos em número mais provável por grama (NMP/g).

\section{RESULTADOS E DISCUSSÃO}

$\mathrm{pH}$

Os valores de $\mathrm{pH}$ observados para o Penaeus brasiliensis + Penaeus paulensis variaram de 7,1 a 8,1 (Tabela I), superando os aceitos pelo Regulamento da Inspeção Industrial e Sanitária de Produtos de Origem Animal - RIISPOA (Brasil, 1980), para pescado, que define pH máximo de 6,8 para a carne externa e 6,5 para a interna. Superaram, também, em sua maioria, os encontrados na bibliografia consultada, relativos ao camarão "fresco": 6,75 em Penaeus brasiliensis (Luna, 1971); 7,4 em Penaeus aztecus (Flick, Lovell, 1972); 7,05 em Penaeus merguiensis (Shamshad et al., 1990); e 7,6 em Pandalus jordani (Flores, Crawford, 1973).

A variação do $\mathrm{pH}$ parece estar relacionada às condições de armazenamento e procedimentos aos quais é submetido o camarão imediatamente após sua captura (Flores, Crawford, 1973). O pH inicial de 7,05 no caso do Penaeus merguiensis chegou a 8,25, depois de 16 dias de estocagem em gelo $\left(0^{\circ} \mathrm{C}\right)$ e a 8,6 , quando armazenado a $35^{\circ} \mathrm{C}$, durante 24 horas (Shamshad et al., 1990).

O estabelecimento de valores de $\mathrm{pH}$ que correspondessem ao estado de frescor do camarão foi indicado por alguns autores. Bailey et al. (1956) consideraram que em $\mathrm{pH}$ até 7,70 o camarão mantinha as características de um produto 'fresco", acima deste valor e até 7,95 , era considerado de má qualidade, porém aceitável. Valores superiores a 7,95 tornavam desaconselhável o consumo do camarão. Segundo Luna (1971) e Shamshad et al. (1990), $\mathrm{pH}$ acima de 7,2 e de 7,6, respectivamente, caracterizavam produto não-comestível. Se considerado o limite estabelecido por Bailey et al. (1956), pH 7,70, seis lotes (60\%) dos analisados (Tabela I) estariam aptos para consumo. Mas em relação ao limite estabelecido por Luna (1971), $\mathrm{pH} 7,20$, apenas dois lotes (20\%) dos dez analisados poderiam ser consumidos.

\section{Bases Voláteis Totais - BVT}

$\mathrm{Na}$ análise de BVT são determinados compostos básicos nitrogenados voláteis, como a trimetilamina, dimetilamina e amônia, resultantes da ação enzimática autolítica e microbiana sobre proteínas musculares, além de outras substâncias, cujas quantidades variam com o tempo de estocagem, aumentando à medida que a deterioração do pescado avança.

As amostras de camarão-rosa fresco apresentaram valores de BVT entre 27,6 e 73,0 mgN/100 g. Para a maioria $(80 \%)$, os resultados situaram-se acima do limite 
TABELA I - Valores de pH, substâncias reativas ao ácido tiobarbitúrico (TBARs), bases voláteis totais (BVT) e contagens totais de microorganismos mesófilos (CTM) e psicrotróficos (CTP) em camarão-rosa "fresco"

\begin{tabular}{ccccccc}
\hline Lote* & Local** & $\mathrm{pH}$ & $\begin{array}{c}\mathrm{BVT} \\
\mathrm{mgN} / 100 \mathrm{~g}\end{array}$ & $\begin{array}{c}\text { TBARS } \\
\mathrm{mgMA} / \mathrm{kg}\end{array}$ & $\begin{array}{c}\mathrm{CTM} \\
\mathrm{UFC} / \mathrm{g}\end{array}$ & $\begin{array}{c}\mathrm{CTP} \\
\mathrm{UFC} / \mathrm{g}\end{array}$ \\
\hline 1 & $\mathrm{SM}$ & 7,85 & $38,8 \pm 4,2$ & $2,12 \pm 0,01$ & - & - \\
2 & $\mathrm{SM}$ & 7,88 & $49,7 \pm 2,1$ & $1,92 \pm 0,18$ & - & - \\
3 & $\mathrm{M}$ & 7,35 & $32,4 \pm 1,4$ & - & $5,80 \times 10^{3}$ & $1,03 \times 10^{5}$ \\
4 & $\mathrm{M}$ & 7,83 & $34,3 \pm 2,2$ & $0,34 \pm 0,02$ & $1,68 \times 10^{7}$ & $2,50 \times 10^{7}$ \\
5 & $\mathrm{M}$ & 7,70 & $29,4 \pm 2,4$ & $1,66 \pm 0,05$ & $5,50 \times 10^{3}$ & $1,54 \times 10^{5}$ \\
6 & $\mathrm{FL}$ & 8,10 & $73,0 \pm 6,1$ & $1,91 \pm 0,16$ & $2,03 \times 10^{6}$ & $3,00 \times 10^{7}$ \\
7 & $\mathrm{M}$ & 7,09 & $27,6 \pm 1,6$ & $0,17 \pm 0,02$ & $1,02 \times 10^{4}$ & $1,05 \times 10^{4}$ \\
8 & $\mathrm{M}$ & 7,17 & $30,6 \pm 0,2$ & $1,32 \pm 0,13$ & $2,70 \times 10^{3}$ & $3,80 \times 10^{5}$ \\
9 & $\mathrm{M}$ & 7,21 & $34,4 \pm 1,8$ & $1,01 \pm 0,10$ & $2,50 \times 10^{3}$ & $9,70 \times 10^{4}$ \\
10 & $\mathrm{M}$ & 7,41 & $41,2 \pm 3,3$ & $1,36 \pm 0,13$ & $3,60 \times 10^{3}$ & $3,90 \times 10^{5}$ \\
\hline
\end{tabular}

* Lotes de 1 a 6 , amostragens feitas entre abril e maio; lotes de 7 a 10, entre julho e setembro/1999. ** Local das amostragens: $\mathrm{SM}=$ Supermercado, $\mathrm{M}=$ Mercado, $\mathrm{FL}=$ Feira-livre.

de $30 \mathrm{mgN} / 100 \mathrm{~g}$ estabelecido pelo RIISPOA (Brasil, 1980), acima do qual o pescado não está apropriado ao consumo. Savagaon et al. (1972) chegaram a resultados semelhantes aos da Tabela I, analisando o "camarão tropical" (espécie não indicada), que apresentou no primeiro dia de estocagem em gelo concentração de $34,31 \mathrm{mgN} /$ $100 \mathrm{~g}$.

Yeh et al. (1978) encontraram concentrações significativas de adenosina trifosfato desaminase e adenosina monofosfato desaminase, em camarão do Golfo do México, apontando que $50 \%$ da amônia produzida no período inicial do post mortem era pela via enzimática. Com base nesses dados, não pode ser descartada a contribuição enzimática nos resultados de BVT.

Luna (1971) estudou o Penaeus brasiliensis estabelecendo um modelo de qualidade, no qual em concentrações inferiores a $22 \mathrm{mgN} / 100 \mathrm{~g}$, o camarão era considerado fresco; entre 23 e $40 \mathrm{mgN} / 100 \mathrm{~g}$ era comestível, e, com valores acima de $40 \mathrm{mgN} / 100 \mathrm{~g}$, já não estava mais adequado ao consumo. De acordo com a Tabela I, as amostras de camarão-rosa não apresentaram valores de BVT abaixo de $22 \mathrm{mgN} / 100 \mathrm{~g}$, não podendo ser classificado como fresco, segundo Luna (1971). Oito das amostras apresentaram valores inferiores a $40 \mathrm{mgN} / 100 \mathrm{~g}$, caracterizandose como comestíveis. Além de variar em função do tempo de estocagem, os valores de BVT variam principalmente com a temperatura de armazenamento. Shamshad et al.(1990) avaliaram os níveis de BVT durante a estocagem sob diferentes temperaturas e observaram resultados quase duas vezes maiores, quando o camarão era armazenado à temperatura ambiente. Este rápido aumento de BVT em relação a elevadas temperaturas, parece estar relacionado ao aumento na contagem microbiana e à atividade enzimática.

\section{Substâncias Reativas ao Ácido Tiobarbitúrico - TBARS}

A quantificação de TBARS, indicadoras da oxidação lipídica, nas amostras de camarão-rosa resultou em média 1,31 $\pm 0,69 \mathrm{mg}$ de aldeído malônico/kg. Os níveis encontrados coincidem com os relatados para pescado comercialmente fresco (Botsoglou et al., 1994).

\section{Contagem Microbiana}

As contagens de microrganismos mesófilos e psicrotróficos na porção comestível de camarão-rosa variaram de $2,5 \times 10^{3}$ até $1,7 \times 10^{7} \mathrm{UFC} / \mathrm{g}$ e de $1,1 \times 10^{4}$ a 3,0 x $10^{7} \mathrm{UFC} / \mathrm{g}$, respectivamente (Tabela I). Os critérios microbiológicos para a contagem padrão em placas de microrganismos aeróbios, segundo a ICMSF - International Commission on Microbiological Specification for Food (1986), estabelecem o limite máximo de $10^{7} \mathrm{UFC} / \mathrm{g}$ para crustáceos crus congelados. Dessa forma, apenas os lotes 4 e 6 apresentaram contagens acima desse limite.

O camarão pode apresentar diferentes contagens microbianas em função do local de captura e da época do ano, que parecem estar relacionadas com alterações nas características da água, tais como oscilações de temperatura, salinidade, atividade do fitoplâncton, níveis de oxigenação e pH (Vanderzant et al., 1971). Após a captura, o crustáceo torna-se exposto à contaminação em mai- 
or ou menor grau, pela transferência de microrganismos presentes no barco e durante o manuseio nas operações de bordo e de terra. A higiene insatisfatória dos porões dos barcos pesqueiros, onde o camarão é armazenado, a qualidade inapropriada da água utilizada na fabricação do gelo, bem como da água de lavagem e o transporte em condições de refrigeração inadequadas, têm sido indicados como fatores preponderantes na contaminação póscaptura (Pedraja, 1970; Germano et al., 1993). O que ocorre, então, é a substituição da flora aquática original marinha pela de origem terrestre. $\mathrm{O}$ crescimento microbiano durante a estocagem, a bordo ou em terra, principalmente de psicrotróficos, e a atuação das enzimas musculares levam aos processos deteriorativos (Pedraja, 1970). A manutenção do camarão a baixas temperaturas durante o armazenamento e transporte é sem dúvida essencial, principalmente quando se considera que nestas condições o crescimento microbiano ainda continua acontecendo.

\section{pH x BVT x Contagem microbiana}

Foi observada forte correlação $\left(r^{2}=0,85\right)$ entre as contagens de mesófilos (CTM) e psicrotróficos (CTP) e entre esta última (CTP) e o $\mathrm{pH}$, demonstrando que maior contagem microbiana implica maior valor de $\mathrm{pH}$. Correlações menores, porém não menos significativas, foram verificadas entre as BVT e o $\mathrm{pH}\left(\mathrm{r}^{2}=0,70\right)$ e entre as BVT e a contagem de psicrotróficos (CTP) $\left(\mathrm{r}^{2}=0,68\right)$. O pH apresentou, de um modo geral, boas correlações com os demais testes realizados. Não houve correlação significativa entre as TBARS e os parâmetros ensaiados (Tabela II).

TABELA II - Correlação entre os indicadores de qualidade: $\mathrm{pH}$, substâncias reativas ao ácido tiobarbitúrico (TBARs), bases voláteis totais (BVT) e contagens totais de microorganismos mesófilos (CTM) e psicrotróficos (CTP)

\begin{tabular}{lcccc}
\hline & $\mathrm{pH}$ & BVT & TBARS & CTM \\
\hline CTP & 0,85 & 0,68 & 0,36 & 0,85 \\
CTM & 0,78 & 0,51 & $-0,03$ & \\
TBARS & 0,59 & 0,54 & & \\
BVT & 0,70 & & & \\
\hline
\end{tabular}

Pôde-se observar heterogeneidade entre os lotes e dentro de cada lote. Isso porque as alterações organolépticas, bacterianas ou enzimáticas autolíticas observadas em produtos marinhos são particulares para cada indivíduo, de acordo com a sua composição muscular (Pedraja, 1970). Desta forma, os camarões capturados em um mesmo local não apresentarão necessariamente as mesmas características e poderão demonstrar alterações diferentes ao longo da estocagem.

\section{CONCLUSÕES}

A qualidade do camarão-rosa analisado foi considerada insatisfatória com base nos valores de $\mathrm{pH}$ e nos níveis de BVT encontrados. As possíveis razões para este fato estão relacionadas às práticas inadequadas de manipulação e acondicionamento durante o seu transporte e sua comercialização. A implantação de programas de controle de qualidade, embasados inicialmente nas boas práticas de manipulação que contemplem a adequação da infra-estrutura dos barcos pesqueiros, principalmente em relação à cadeia de frio, associada ao treinamento dos manipuladores a bordo e em terra, no próprio comércio varejista, em muito contribuiriam para a melhoria da qualidade apresentada pelo camarão.

\section{ABSTRACT}

\section{Chemical and microbiological quality of pink shrimp sold in São Paulo}

It is necessary to take special care when catching, handling and distributing shrimps in order to keep them in adequate conditions for future consumption. The objective of this study was to evaluate the quality of pink shrimp sold in São Paulo, Brazil. Samples of this crustacean were submitted to VBN (Volatile Basic Nitrogen), TBARS (Thiobarbituric Acid-Reactive Substances), $p H$ and microbial analyses (Mesophilic and Psychrotrophic Plate Counts). These tests together are suitable parameters to evaluate the fish quality. The analyses of the samples showed the following results: the $\mathrm{pH}$ values ranged from 7.09 to 8.10 , the VBN values ranged from 27.6 to $73 \mathrm{mgN} / 100 \mathrm{~g}$, the TBARS values ranged from 0.17 to $2.12 \mathrm{mg}$ malonaldehyde/kg, the Mesophilic Plate Counts ranged from $2.5 \times 10^{3}$ to $1.7 \times 10^{7} \mathrm{UFC} / \mathrm{g}$, and the Psychrotrophic Plate Counts ranged from $1.1 \times 10^{4}$ to $3.0 \times 10^{7} \mathrm{UFC} / \mathrm{g}$. The results suggest that the pink shrimp analyzed had an unsatisfactory chemical quality incompatible with a product sold as fresh.

UNITERMS: Shrimp. Quality. Microbiology. TBARS. BVT. $p H$.

\section{AGRADECIMENTOS}

Agradecemos à FAPESP, pelo suporte financeiro, e à CAPES, pela bolsa de estudo concedida à autora Andréa 
Figueiredo Procópio de Moura. Agradecemos, ainda, ao Professor Motonaga Iwai (IO/USP), pela identificação zoológica das espécies de camarão-rosa.

\section{REFERÊNCIAS BIBLIOGRÁFICAS}

ANALYTICAL METHODS COMMITTEE. Recommended general methods for the examination of fish products. Analyst, London, v.104, p.434-450, 1979.

BAILEY, M. E.; FIEGER, E. A.; NOVAK, A. F. Objective test applicable to quality studies of ice stored shrimp. Food Res., Champaign, v.21, p.611-620., 1956.

BOTSOGLOU, N. A.; FLETOURIS, D. J.; PAPAGEORGIOU, G. E.; VASSILOPOULOS, V. N.; MANTIS, A. J.; TRAKATELLIS, A. G. Rapid, sensitive, and specific thiobarbituric acid method for measuring lipid peroxidation in animal tissue, food, and feedstuff samples. J. Agric. Food Chem., Washington, v.42, p.1931-1937, 1994.

BRASIL. Ministério da Agricultura. Regulamento da Inspeção Industrial e Sanitária de Produtos de Origem Animal, Brasília, 1980. 166p. [Decreto n.1255, de 25 de jun 1962].

COUSIN, M. A.; JAY, J. M.; VASAVADA, P. C. Psychrotrophic microorganisms. In: VANDERZANT, C., SPLITTSTOESSER, D. F., ed. Compendium of methods for the microbiological examination of foods. New York: American Public Health Association, 1992. p.153-168.

FLICK, G. J.; LOVELL, R. T. Post-mortem biochemical changes in the muscle of gulf shrimp, Penaeus aztecus. J. Food Sci., Chicago, v.37, p.609-611, 1972.

FLORES, S. C.; CRAWFORD, D. L. Postmortem quality changes in iced pacific shrimp (Pandalus jordani). $J$. Food Sci., Chicago, v.38, p.575-579, 1973.

GERMANO, P. M. L.; OLIVEIRA, J. C. F.; GERMANO, M. I. S. O pescado como causa de toxinfecções bacterianas. Hig. Aliment., São Paulo, v.7, n.28, p.40-45, 1993.

INSTITUTO BRASILEIRO DE GEOGRAFIA E ESTATÍSTICA. Pesquisa de orçamentos familiares. [on line]. Disponível em: http://www.sidra.ibge.gov.br/cgibin/prtabl Acesso em: 29 jan. 2000.
INSTITUTO BRASILEIRO DE MEIO AMBIENTE E DOS RECURSOS NATURAIS RENOVÁVEIS. Estatística de Pesca. [on line]. Disponível em: http:// www.ibama.gov.br/atua.html. Acesso em 29 jan. 2000.

INSTITUTO ADOLFO LUTZ. Normas analíticas do Instituto Adolfo Lutz: métodos químicos e físicos para análise de alimentos. 3 ed. São Paulo: Instituto Adolfo Lutz, 1985. 533p.

INTERNATIONAL COMMISSION ON MICROBIOLOGICAL SPECIFICATIONS FOR FOODS. Microorganisms in Foods. 2. Sampling for Microbiological Analysis: Principles and Specific Applications. 2ed. Buffalo: University of Toronto Press,1986. [on line]. Disponível em: http:// seafood.vcdavis.edu/organize/icmsf.htm Acesso em: 26 jan. 2003.

LUNA, G. A. L. Cambios quimicos y microbiologicos en la decomposicion de camarones (Penaeus brasiliensis). Control de calidad para muestras del mercado. Arch. Latinoam. Nutr., Caracas, v.3, p.381-400, 1971.

MATURIN, L. J.; PULER, J. T. Food and Drug Administration of the United States of America Bacteriological Analytical Manual. Gatthesburg: American Association of Analytical Chemists, 1995. p.3.01-3.09.

NATIONAL FISHERIES INSTITUTE. The Shrimp council. [on line]. Disponível em: http://www.nfi.org/ Shrimp\%20Council/SR080797.htm Acesso em: 20 ago.1998.

PEDRAJA, R. R. Change of composition of shrimp and other marine animals during processing. Food Technol., Chicago, v.24, p.1355-1360, 1970.

SAVAGAON, K. A.; VENUGOPAL, V.; KAMAT, S. V.; KUMTA, U. S.; SREENIVASAN, A. Radiation preservation of tropical shrimp for ambient temperature storage. 2.Storage studies. J. Food Sci., Chicago, v.37, p.151-153, 1972.

SHAMSHAD, S.I.; KHER-UN-NISA, R. M.; ZUBERI, R.; QADRI, R.B. Shelflife of shrimp (Penaeus merguiensis) stored at different temperatures. J. Food Sci., Chicago, v.55, n.5, p.1201-1205, 1990. 
YEH, C. S.; NICKELSON, R.; FINNE, G. Ammoniaproducing enzymes in white shrimp tails. J. Food Sci., Chicago, v.43, n.5, p. 1400-1401, 1404, 1978.

VANDERZANT, C.; NICKELSON, R.; JUDKINS, P. W. Microbial flora of pond-reared brown shrimp (Penaeus aztecus). Appl. Microbiol., Washington, v.21, n.5, p.916921, 1971.
VYNCKE, W. Direct determination of the thiobarbituric acid value in thricloracetic acid extracts of fish as a measure of oxidative rancidity. Fette Seifen Anstrichmittel, Leinfelden, v.72, n.12, p.1084-1087, 1970.

Recebido para publicação em 26 de julho de 2002. 